\title{
A Travel Theme TV Reality Show in Relation to Travel Export: "Welcome, First Time in Korea?" as a Case Study
}

\author{
Ji Soo Park1), Kyung Mi Bae2)
}

\begin{abstract}
This study focuses on the significant changes to the response and perception of the spectators of the show, Welcome, First Time in Korea? in relation to travel export in international trade of South Korea. Following the new trend of increasing TV travel programs, this research is of utmost importance in recognizing factual outcomes reflecting the impact on tourism in Korea which one of the travel theme based TV reality show leads to. Analysis is made on the Internet based searching which allowed credible responses and numbers. This chosen case of Welcome, First Time in Korea? is analyzed in-depth and it will be compared to the other two reality shows carrying the aspect of travel export. Then, considerations for outer opportunity features will be discussed by that of exterior threatening factors and lastly, suggestions to tackle with threats will be analyzed. This study indicates the outcome and the correlation between the exterior factors, opportunities and threats, and the change in viewers' perceptions which affects tourism in Korea in the perspective of export in international trade.
\end{abstract}

Keywords : Seoul Mate, Travel Export, Traveler's Guide to My Room, TV Reality Show, Welcome, First Time in Korea?

\section{Background}

Nowadays, myriad TV programs introduce unique and unknown landmarks in various countries to the audience. External impetuses whether they be positive or negative, induce or discourage the aim for travelers both foreigners and local residents to come to Korea, having been fascinated to unique Korean culture, tradition, infrastructures, landmarks, food, leisure activities, and amongst other features demonstrating the true and deep culture of Korea. Nowadays, travel TV shows in reality format have become world's norm and about $20 \%$ of global travelers have visited a destination after encountering it on a TV show[1]. Besides, technological development along with advanced mobile industry especially in the Fourth Industrial Revolution era play pivotal roles in advertising travelling spots broadcasted in the

Received(July 18, 2018), Review Result(1st: July 31, 2018, 2nd: August 27, 2018), Accepted(September 10, 2018)

1) (Student) Dept. of International Trade \& Regional Studies, INHA University, 100 Inharo, Nam-gu, Incheon 22212 email: b.b_jsp@hotmail.com

2) (Assistant Professor, Corresponding Author) Dept. of International Trade \& Regional Studies, INHA University, 100 Inharo, Nam-gu, Incheon 22212 email: gracebae@inha.ac.kr 
TV show. The data showing $1700 \%$ increase in mobile bookings in travel[2], the fact that Asian travelers are most likely to use online means to book accommodation[3], and that big data allows true personalization of travel preference of each customer[4] all enable the show to obtain greater advertising impact upon tourism in Korea. Lastly, the growth of Hallyu, the K-wave, has also attracted tourists to the country in recent years[5] and carried out favorable effect on the TV show to acquire positive impact upon tourism. Similarly, $28.3 \%$ of Hong Kong residents cited Korean drama series and TV programs as the most important potential reason they might visit Korea[5]. Overall, the above mentioned surrounding opportunity factors empower the show, 'Welcome, First Time in Korea?', to have great impact upon the viewers.

\section{Case Analysis}

\subsection{Special Features of "Welcome, First Time in Korea?"}

Pointing out special features and contents of the reality TV show "Welcome, First Time in Korea?" is fundamental in that the findings will enable more specific analysis on which factors are actually contributing to Korea's tour export. Special features are captivating the spectators of the show and in fact, the show has earned the first place for 2018 Korean First Brand Award as the best travel TV program. Sponsored by Korea Consumer Forum, 2018 Korean First Brand Award is based on the results from nation-wide consumers vote and awarded to a TV show that will eventually lead the next year's trend[6]. The fact that the show has been graded as the best and the outcome of consumers vote substantiate there really exist the aspects that attract many viewers. Show's containment of novelty or inverse concept, authenticity, and lastly stimulus of viewers' curiosity in the characters depicted in the show all support the fame of "Welcome, First Time in Korea?"

\subsubsection{Inverse Concept of Bringing Foreigners into Korea}

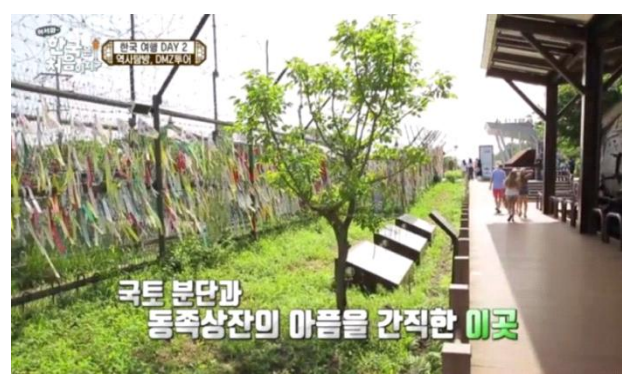

[Fig. 1] German Guests' Visit to DMZ [7]

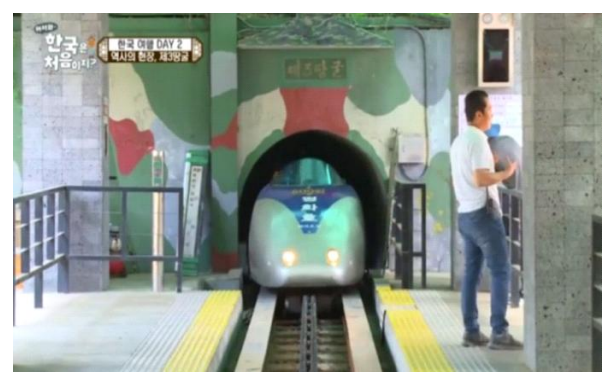

[Fig. 2] The Third Tunnel [7] 
To begin with, the success of "Welcome, First Time in Korea?" is from differentiation from competitors in the market in which many Korean reality TV shows travel around the world to show how people abroad live[8]. On the other hand, the program focuses on showing how exotic Korea can be in the eyes of foreigners[9]. Indeed, the show takes another spin on the presence of foreigners on Korean media by inviting alien people from abroad[9]. In the show, a number of foreign friends invited by one famous foreign figure, mostly talk-show panelist working in Korea, travel and encounter Korea's unique aspects, and the guests' reactions towards the unknown country are inspected and captivate the viewers.

Hence, the show's new and inverse concept of foreigners' traveling in Korea provides the local audience with the novel pleasure and vicarious satisfaction[10] and allows second thoughts and new feelings to everyday life encountering that Koreans are already so accustomed to[11]. Also, the format of "Welcome" in which a foreign host, who can speak fluent Korean, is left in awe with Korea's unique culture, showing true admiration for the country arouses high national pride among local viewers[12]. In one of the episodes of the show, guests from Germany visited the Demilitarized Zone between North and South Koreas, toured the Third Tunnel, a massive secret underground passage made by North Korea, and were affected by the sad story of two Koreas' separated families with deeper understanding of the grief as Germans have experienced the same history. According to an online survey conducted by PMI, the DMZ visit by German guests was the most impressive scenes for the audience[11].

\subsubsection{Authenticity: Real Reality TV Show}
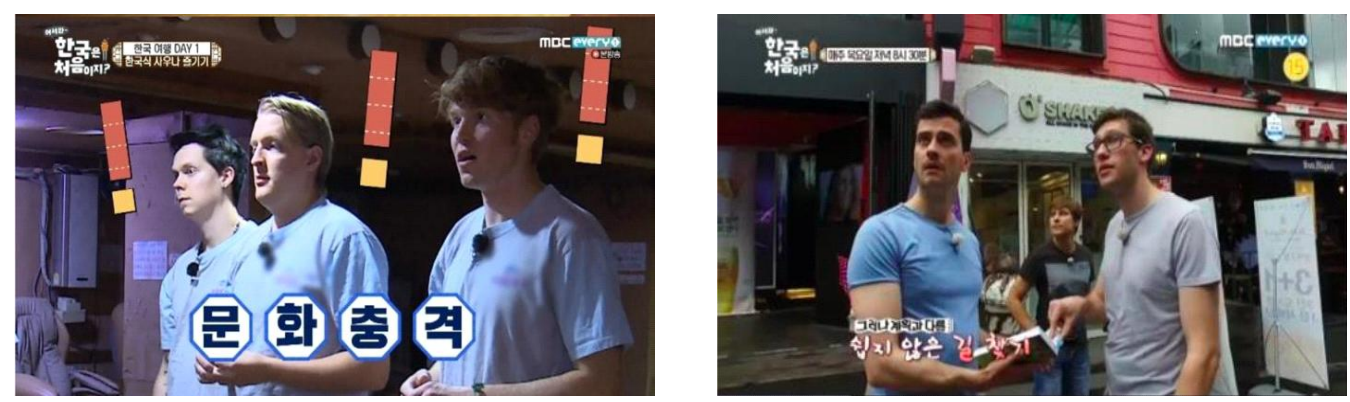

[Fig. 3] Finnish Guests' Visit to Korean Sauna [13] [Fig. 4] Germans Getting Lost [14]

In addition to the differentiated concept, the program's authenticity contributes greatly to the success of "Welcome, First Time in Korea?". TV critics stated that genuine and honest portrait of Korea through the lens of down-to-earth guests from abroad allows the show to attract more and more watchers[15]. Besides setting the overall framework, there is no reflection of 
production staffs' wants and needs in the program, and thus all travel itinerary is planned by foreign host in an unpredictable, impromptu way[12]. The kind of authenticity of "Welcome" accompanies more uncertainty as language barrier makes harder for guests to communicate with local people even with a translator who actually does not intercede in various situations throughout the tour[8]. Episodes of the Finnish panel members earned high rating with very honest portrait of South Korea. In fact, according to the same online survey by PMI, Finnish guests' visit to convenience Jjimjilbang was selected as the second best scenes with $21.4 \%$ of all 1984 surveyees[10].

\subsubsection{Foreign Guests' Unique Characteristics and Perceptions}
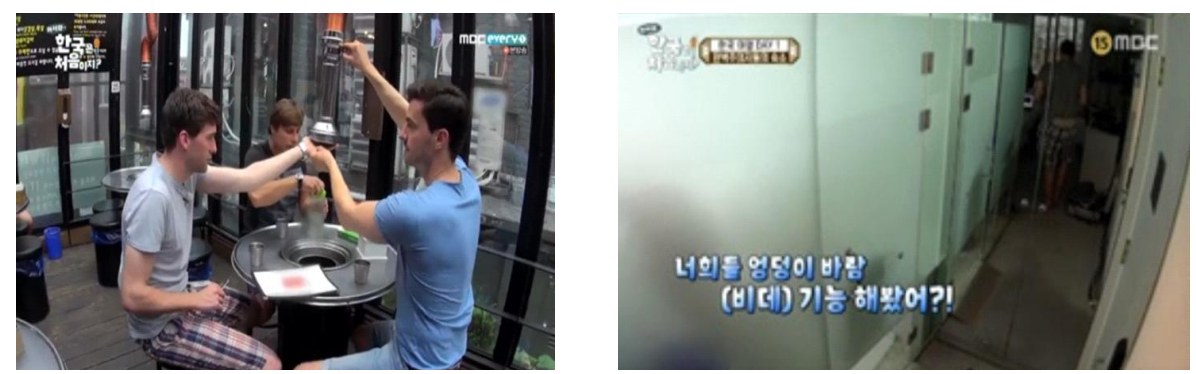

[Fig. 5] German Guests Unfamiliar with Ventilation System[16] [Fig. 6] And with Bidet[17]

Furthermore, viewers' curiosity about and interest in the characters depicted in the "Welcome, First Time in Korea" also account a lot for the popularity of the show. There are three different features of both the guests and hosts: sensitivity even to subtle aspects, earnest passion to learn, and seriousness or tolerance towards the cultural differences. First, the audience appreciate foreigner's sensitivity to ordinary, everyday, or even negligible aspects of Korean culture and the fact leads viewers to rediscover small familiar things they would not otherwise pay attention to such as ventilation fans above Korean barbecue tables and bidets in toilets[9]. Second, what made German friends' journey more special was both foreign host and guests' willingness to learn about true Korea. Foreigners in the show wondered at everything and endeavored to understand the cultural differences, enabling viewers to see the real passion to experience further Korea[11]. Third and last, seriousness of accepting Korean aspects, accompanied by tolerance towards the disparity claimed many views. For instance, German friends deeply dedicated to and very serious about being engaged in Korean culture were well-received by the spectators of the "Welcome" show[8]. Since there are various reality TV shows focusing on traveling of foreigners in Korea or abroad, "Welcome" could also have been 
categorized into 'just another similar travel theme program' However, what saved the show from falling into stereotypical boredom were foreign friends' unique and unprecedented characteristics[18].

\subsection{Comparison in the Perspective of Travel Export}

Now that the special features that support the survival of "Welcome, First Time in Korea?" in harsh competition of Korea's media are discussed, comparing and contrasting with other similarly intended TV programs will allow wider perception on the subject. Analysis on similarities of and differences among three travel theme reality TV shows, "Welcome, First Time in Korea?", "Traveler's Guide to My Room", and "Seoul Mate" all claiming spotlights in and out of Korea and contributing to the increase in exportation of Korea's tourism, will play a pivotal role in discovering the overall impact of export-inducing travel TV programs.

"Traveler's Guide to My Room" is a SBS' SWAP reality documentary series in which guests, both Koreans and foreigners, exchange one another's private rooms for five days in order to directly feel each country's theme and truly localize and melt into new, unaccustomed culture. Olive TV's "Seaul Mate" is also a reality TV show through which foreigners are invited to four Korean celebrities' houses in Seoul where Korean hosts and foreigners interact and overcome several hardships like language barriers and innately different ways of interpretation of surroundings. Certainly, there exist similar aspects that two of the above mentioned shows share with "Welcome, First Time in Korea?" The first and obvious similarity is that all of three programs let foreigners explore Korea through diverse formats.

Additionally, three programs adopt two main concepts- the combination of observational reality show and travel theme show[19]. In other words, each show focuses on observing attitudes of the invited guests from the opposite sides of the world, expecting previously unseen, peculiar reactions from foreigners and at the same time, depicts features related to traveling in Korea. As regards the episodes of "Seoul Mate" viewers showed interest towards how Tilly, one of the invited guests, reacts after eating spicy Korean food[20]. Thirdly, the existence of mediators who are already somehow familiar to local settings is another similarity three TV programs share. In case of "Welcome," a host, also a foreigner, who has been settled in Korea for a period of time and is a friend of invited guests plays the role of a guide. Regarding "Guide to My Room" a friend of the owner of the room who has been bound for foreign country, acts as the mediator who introduces the manual of the room for the invited foreigner. Finally in "Seoul Mate" Korean casts who have decided to share rooms with 
A Travel Theme TV Reality Show in Relation to Travel Export: "Welcome, First Time in Korea?" as a Case Study

foreigners are the ones who take the guests around Seoul.

On the contrary, there surely are the features that create gaps among three different shows. First, the differences between "Welcome, First Time in Korea?" and "Traveler's Guide to My Room" will be discussed, and comparison of "Welcome" with "Seoul Mate" will follow.

\subsubsection{Welcome, First Time in Korea? vs. Traveler's Guide to My Room"}

First fundamental disparity of "Welcome" and "Guide to My Room" starts with the fact that the latter provides simultaneous depiction of Korean people encountering culture overseas and of foreigners getting to know unfamiliar Korea. Thus, the original theme of "Guide to My Room" is exchanging private rooms between foreign artists and Korean celebrities. Whereas "Welcome" focuses only on foreigners whether they be host or guests visiting Korea, "Guide to My Room" rather shows many different cities in different continents and puts emphasis on both foreign and local guests at the same time[21]. Secondly, "Welcome" concentrates really on outer factors. For example, the show spotlights foreigners' behaviors through certain activities such as travelling landmarks, eating food, and experiencing tradition that can be done uniquely in Korea. On the other side of the coin, "Guide to My Room" rather attempts to reveal the inner sides of guests through inspecting guests' artistic characteristics, perspectives, and personal ways of adopting to unfamiliar situations. Likewise, "Guide to My Room" scrutinizes both local and foreign people's own philosophy, allowing the audience to really feel the theme of each country[19]. Third and final significant gap between two TV programs comes from the fact that in "Welcome," production crew do not intervene in travel decision-makings of foreigners and thus the show starts with undecided settings and locations. However, in "Guide to My Room" staffs select rooms and provide instructions beforehand[22].

\subsubsection{Welcome, First Time in Korea? vs. Seoul Mate}

"Seoul Mate", another export-related TV reality show in Korea, and "Welcome, First Time in Korea?" differ in three contrasting ways. First of all, "Welcome" depicts foreigners who have visited Korea for the first time. The guests are truly alien to the unique aspects of Korea and the novel experiences leave shocking but interesting impacts both to the audience and travelers themselves. On the other hand, the basic system of "Seoul Mate" starts with the voluntary applications from foreigners who are somehow already fond of Korea[23]. Hence, the starting points of two shows are completely different. Moreover, the main aspects two shows are trying to highlight also vary. In the case of "Seoul Mate," the program, though makes foreign guests appear frequently, actually provides Korean hosts-oriented story telling[24]. While "Welcome" 
inspects foreigners' reactions to whole new culture or taste of local food (guests-oriented), the main plot of "Seaul Mate" comes from how hosts, Korean celebrities' will respond in interaction with foreign guests[25]. Last but not least, similar to what has been mentioned above for comparison of "Welcome" with "Guide to My Room" in "Seaul Mate" invited foreigners are asked to live in Korean celebrities' places, already selected by production staffs, for two days and three nights[26].

\subsubsection{Similarities and Differences}

All in all, "Welcome, First Time in Korea," "Traveler's Guide to My Room" and "Seoul Mate" share three similarities. First, three TV shows intend to export Korean tourism to the watchers whether they be foreigners or local people. Second, all programs combine two concepts of observational reality and travel theme, observing foreigners' unique ways of dealing with Korean culture and overcoming difficulties when travelling around the country. Lastly, there exists a mediator in each show with a job of making sure foreign travelers are on the right track. On the other hand, although all three shows are travel themed, especially of exporting Korea tourism, there are still special features that each show attains. First difference between "Welcome" and "Guide to My Room" is that whereas the former focus foreigners in Korea, the latter provides simultaneous depiction of both foreigners in Korea and Koreans in foreign countries. Furthermore, "Welcome" concentrates really on showing landmarks, food, and culture of Korea but "Guide to My Room" rather describes the inner characteristics of visitors, so the reactions that could be depicted not because of cultural differences but because of personal disparities. Thirdly, the intervention of production staffs of each show in decision-makings of the visitors differ in extent. Now, contrasting to the fact that "Seoul Mate" invites foreigners who are already accustomed to Korea, "Welcome" shows foreigners who have never been to the country. Secondly, "Seoul Mate" provides Korean hosts-oriented story telling, unlike visitors-oriented theme of "Welcome" Also, the intervention of production staffs as a guidance of two shows differs in scope.

Through analyzing similarities and differences, it is recognizable that although three Korean TV shows share the concept of observational, travel reality program, each show puts extra emphasis on the special features in order to compete in the harsh competition of TV channels with intention of exporting Korean tour services. 


\section{Discussions and Suggestions}

Factors for external opportunity need to be examined first in order to recognize which surrounding aspects trigger positive impression about Korea's tour services, products, sites, and culture on the watchers of the 'Welcome, First Time in Korea?' First and foremost, the world's current trend fosters tourism and allows more chances to go abroad. In addition to this, Korea's hosting of the 2018 Winter Olympics and the country's heavily invested winter sports infrastructure captivate more international visitors to the country[27]. These features are another exterior opportunity factors which provide the show to develop specific tactics to attract more viewers who might eventually become the future consumers of tour services and products in Korea. When fostered by the fact that both Europe and America already have great ski destinations unlike Asia[28], the 2018 Winter Olympics with advanced winter sports facilities can bring about astounding effects on the advertisement both of the TV show and Korea's tourism industry.

Moreover, the analysis of external threat factors, discouraging 'Welcome, First Time in Korea?' from appealing to the viewers to visit Korea is a sine qua non. First of all, current diplomatic situations including THAAD (Terminal High Altitude Area Defense missile) related problems with the Chinese government and protectionism with accompanied strict polices of the U.S. demonstrate how political issues dwindle the demand of the TV show viewer's travelling to Korea. China's decision to boycott South Korea's tourism industry costs the economy of Korea about 7.5 trillion won and the number of Chinese tourists visiting Korea has plunged more than $60 \%$ in 2017, compared to that of 2016[29]. Also, the strengthening of the U.S. trade protectionism will undoubtedly have a negative effect on Korea's tourism industry which results in falling impact of the show on viewers overseas[30]. Additionally, high competition with other similarly intended reality TV shows can be another aspect threatening the advertising effect of 'Welcome, First Time in Korea?'. Mnet's 'Launch My Life', tvN's 'Flowers Over' series, 'New Journey to the West', 'Youn's Restaurant', 'Salty Tour', JTBC's 'Where's My Friend's House' and KBS's 'Battle Trip' are only few examples of TV programs mainly intended for the import of foreign tour services and products into Korea, introducing fascinating features of travelling abroad[31]. On the other hand, with the same intention of the exportation of Korean tourism industry to foreigners overseas, TV programs such as, SBS's 'Running Man', tagTV's 'Hong's Korea Instruction Manual' backed up by the popularity of Korean actress, Hong, and KBS's '2 Days 1 Night' are also recognized as true threatening 
competitors to 'Welcome, First Time in Korea?'. Surely, harsh competition decreases the impact 'Welcome, First Time in Korea?' has upon leading the viewers to Korea.

Furthermore, several suggestions are proposed for further application to the show in order to overcome external, outer threats. To tackle with political threatening factors like THAAD and protectionism related issues, the show, 'Welcome, First Time in Korea?', first needs to include contents targeting more diversified consumers, not only focusing on European guests but also on guests with diverse ethnicities and nationalities. In such way, broadening of the international demand market will be realized, which will eventually decrease the intensity of threats from diplomatic situations with China and the U.S. With the fact that Korea's tourism industry also concentrates on the burgeoning Muslim tourism numbers after losing Chinese tourists[32], the need for the TV show to widen the diversity of viewers remains crucial. In addition, survival from the harsh competition in the market of travel TV programs starts from direct communication with the audience which seems very weak in 'Welcome, First Time in Korea?', and acceptance of people's opinion through online voting system and competition features in which the winner is chosen by the audience, so that feelings of participation and sympathy can occur. Also, if the show depicts more scenes of foreign guests and Korean local people communicating with difficulty along with storytelling contents, earning of high view from and applying of impact on the audience will be feasible. Through scrutinizing and dealing with outer threatening factors based on the stated suggestions, should the show be able to strengthen the contents and progress further.

\section{Conclusion}

All in all, the above mentioned external factors are triggering significant changes both in the mind and the number of tourists visiting specific places in Korea, introduced in the show. The data along with statistics indicate that current world's trend, the fact that Korea is the host of the 2018 Winter Olympics, technological advancement, and the growth of K-wave, Hallyu, are the opportunity factors which induce the aim of the audience to come to Korea and encounter Korean culture. On the other hand, complex diplomatic situations with other countries' strong stance against Korea's tourism industry and more than high competition in the market of travel TV show are considered as surrounding threats, discouraging the viewers from travelling in Korea. 


\section{References}

[1] TripBarometer, The tour and activity industry: a multi-billion dollars market, Trekk Soft, (2015)

[2] F. Gonzalo, Mobile-optimised businesses are ahead, Trekk Soft, (2016)

[3] TripBarometer, Mobile-optimised businesses are ahead, Trekk Soft, (2015)

[4] W. Jones, The Industry 4.0 and travel: Bringing 'Smart Travel' together, Sabre, (2017)

[5] Oxford Economics, The Economic Contribution of the Film and Television Industries in South Korea, Oxford Economics, (2011)

[6] Y. R. Kim, Welcome, First Time in Korea?, Awarded the best picture from TV broadcasting part at Korea's PD Awards, March 16, (2018)

[7] S. J. Baek, Welcome, First Time in Korea? Their visit to DMZ inspired the viewers want to visit also, Global Economics, September 1, (2017)

[8] Korea Bizwire, Shows Featuring Foreigners in South Korea Reaches "Record" 3.5 Percent Ratings, The Korea Bizwire, (2017)

[9] R. Doo, TV shows give fresh insight into Korea through eyes of foreign visitors, The Korea Herald, (2017)

[10] HaB Korea, "Welcome, First Time in Korea?" confirmed the regular program, HaB Korea, (2017)

[11] D. H. Jung, "Welcome" might be the best reality TV show this year, Enter Media, (2017)

[12] G. E. Yoon, Inverse Concept contributing to the fame of "Welcome, First Time in Korea?". Yonhap Daily News, (2017)

[13] D. H. Nam, Welcome, First Time in Korea? Finnish having cultural shock at sauna in Korea, Star Hankook, November 23, (2017), Image.

[14] J. Y. Woo, How a reality show on first-timers' travel to Korea grabs TV audiences, Yanhap News, May 10, (2018), Image

[15] H. S. Yim, Surging Interest in Finland after Success of "Welcome, First Time in Korea?", Korea Bizwire (2017)

[16] R. Doo, TV show give fresh insight into Korea through eyes of foreign visitors, The Korea Herald, September 24, (2017), Image

[17] H. Y. Yoon, TV On air, Welcome, First Time in Korea? Not funny Germans? cute, innocent beauty they radiate, TV Daily, September 19, (2017), Image

[18] H. J. Gho, The Reason for the Fame of "Welcome, First Time in Korea?", Kyunghyang Daily News, (2017)

[19] H. S. Yeon, "Guide to My Room" limits to just looking around a room, not living, TV Daily, (2017)

[20] H. J. Jeon, A host in "Seoul Mate" changes his job with Turkish guests, Sports Donga, (2018) 
[21] J. H. Kim, "Guide to My Room", similar but different art travels between casts, TV Daily, (2017)

[22] G. S. Kim, Ultra luxurious casting cannot help "Guide to my Room", Enter Media, (2017)

[23] G. E. Yoon, "Cultural Shock"- The Fame for Foreigners Observational Reality TV Show, Yonhap Daily News, (2018)

[24] M. H. Kim, CP Park of "Seoul Mate" says the show will differentiate itself from "Welcome", Star News, (2017)

[25] Y. E. Shin, "Seoul Mate": Another foreign-oriented show? Will it be different from "Welcome" and "My Foreign Friend", Maeil Economics Star Today, (2017)

[26] J. H. Park, Foreigners + First visit to Korea= Fame of "Welcome, First Time in Korea?", Kukmin Daily, (2017)

[27] N. Farhan, Can the Winter Olympics benefit snow sports tourism in South Korea?, Channel News Asia, (2017)

[28] D. Roelofs, Can the Winter Olympics benefit snow sports tourism in South Korea?, Channel News Asia, (2017)

[29] E. Hwang, China inflicted a world of pain on South Korea in 2017, South Korea's National Assembly's Budget Office, (2017)

[30] B. H. Jang, U.S. protectionism poses threat to S. Korean economy: BOK official, Yonhap News, (2017)

[31] M. S. Lee, "It's summer. Let's travel." Innovative TV Travel Programs Blast, KOFICE, (2017)

[32] R. Premack, After Losing Chinese Tourists, South Korea Wants To Grow Its Burgeoning Muslim Tourism Numbers, Forbes, (2017) 